\title{
Local Allergic Nasal Reactions Convert to Classic Systemic Allergic Reactions: A Long-Term Follow-Up
}

\author{
Joachim Sennekamp ${ }^{a}$ Isabella Joest ${ }^{a} \quad$ Birgit Filipiak-Pittroff $^{b}$ \\ Andrea von Berg $^{\mathrm{b}}$ Dietrich Berdel ${ }^{\mathrm{b}}$ \\ ${ }^{a}$ Malteser Lung and Allergy Center, Bonn, and besearch Institute, Children's Department, Marien-Hospital, \\ Wesel, Germany
}

\section{Key Words}

Local allergy $\cdot$ Nasal allergen challenge $\cdot$ Rhinitis $\cdot$ Skin test . Antigen-specific lgE

\begin{abstract}
Background: There is poor knowledge about the evolution of the negative skin test in local allergy over time. Does the negative skin test of patients with local allergies remain negative permanently or does it become positive? Methods: We describe our long-term observation concerning the evolution of the negative skin test over time. This is a retrospective, follow-up study using data from the medical records of a group of patients with local allergy. A total of 42 patients aged between 3 and 70 years (median age: 31.5 years) were studied. The duration of follow-up varied from 1 to 27 years. Skin tests were performed using the skin-prick test and intracutaneous techniques for pollen, molds, mites, feathers (goose and duck) and animal danders. Nasal provocation tests were conducted with the same allergens. Additionally, specific lgE in 17 patients was measured by enzyme allergosorbent test. Results: During the period of observation, the negative skin test reactions converted into positive reactions in 17 patients (40\%). In addition to the negative skin reactions, $55 \%$ of the patients also presented positive skin reac-
\end{abstract}

tions. The conversion rate was higher in children and adolescents than in adults. In 4 patients, conversions occurred $>7$ years after the initial examination. Specific lgE was negative in all but 2 patients, in whom the conversion in the skin test was accompanied by a switch from negative to positive specific IgE. Conclusion: Conversions from local to classic systemic respiratory allergic reactions appear to be a common phenomenon.

(c) 2015 S. Karger AG, Basel

\section{Introduction}

Local allergic rhinitis is characterized by a positive response to the nasal allergen provocation test while the skin test reaction (skin-prick test (SPT) or intracutaneous (i.c.)) to the same allergen is negative. Specific IgE identified using the enzyme allergosorbent test (EAST) can be detected in nasal secretions but not in the serum of these patients [1]. This type of allergy is limited to the nasal mucosa and therefore referred to as local allergic rhinitis [2, 3], entopy [4] or allergic rhinitis with a negative skin test [5]. Clinical symptoms, nasal secretions and the profile of cytokine production of local allergic rhinitis are similar to classic allergic rhini-

\section{KARGER 125}

(c) 2015 S. Karger AG, Base

$1018-2438 / 15 / 1662-0154 \$ 39.50 / 0$

E-Mail karger@karger.com

www.karger.com/iaa
Correspondence to: Prof. Dr. Joachim Sennekamp

Malteser Lungen- und Allergiezentrum Bonn DE-53113 Bonn (Germany)

E-Mail Joachim.Sennekamp@ malteser.org 
Table 1. Skin tests and specific IgE in patients with positive nasal provocation test and whose skin tests converted from negative to positive

\begin{tabular}{|c|c|c|c|c|c|c|}
\hline \multirow[t]{2}{*}{ No. } & \multirow[t]{2}{*}{ Age, years ${ }^{\mathrm{a}}$} & \multicolumn{2}{|c|}{ Elapsed time from initial skin test } & \multirow[t]{2}{*}{ EAST class $^{\mathrm{b}}$} & \multirow[t]{2}{*}{ Allergen } & \multirow[t]{2}{*}{ SPT/i.c. } \\
\hline & & $\begin{array}{l}\text { to last negative } \\
\text { skin test }^{c}\end{array}$ & $\begin{array}{l}\text { to first positive } \\
\text { skin test }\end{array}$ & & & \\
\hline 1 & 53 & 7 & 27 & & mites & i.c./i.c. \\
\hline 2 & 36 & 7 & 10 & & mites & i.c./i.c. \\
\hline 3 & 6 & 8 & 13 & & tree pollen & SPT/i.c. \\
\hline 4 & 25 & 11 & 14 & & grass pollen & $\mathrm{SPT} / \mathrm{SPT}$ \\
\hline 5 & 55 & - & 11 & & mites & i.c./i.c. \\
\hline 6 & 3 & 4 & 8 & $0 / 4$ & mites & $\mathrm{SPT} / \mathrm{SPT}$ \\
\hline 7 & 5 & 3 & 4 & 0/n.p. & mites & SPT/i.c. \\
\hline 8 & 21 & - & 2 & & tree pollen & i.c./i.c. \\
\hline 9 & 18 & - & 5 & n.p./0 & mites & i.c./i.c. \\
\hline 10 & 33 & - & 17 & n.p./0 & mites & i.c./i.c. \\
\hline 11 & 11 & 1 & 8 & $0 / 0$ & grass pollen & i.c./i.c. \\
\hline 12 & 38 & 5 & 8 & n.p./0 & grass pollen & SPT/SPT \\
\hline 13 & 25 & 1 & 4 & $0 / 0$ & tree pollen & SPT/SPT \\
\hline 14 & 42 & - & 12 & & feathers & i.c./i.c. \\
\hline 15 & 11 & - & 2 & n.p./0 & tree pollen & SPT/SPT \\
\hline 16 & 42 & 2 & 7 & $0 / 0$ & grass pollen & SPT/SPT \\
\hline 17 & 5 & 1 & 2 & n.p./2 & grass pollen/dog & SPT/SPT \\
\hline \multicolumn{7}{|c|}{$\begin{array}{l}\text { n.p. }=\text { Not performed. } \\
\text { a At first skin test. }\end{array}$} \\
\hline
\end{tabular}

tis $[6,7]$. In many patients with local allergic rhinitis, associations with conjunctivitis and asthma are frequent $[7,8]$.

Very little is currently known about the long-term evolution of negative skin test reactions in local allergies [8, 9]. In 1987, we observed local allergic reactions in 102 patients [10]. In 15 of these, we conducted a second skin test within 3 years; 6 patients reacted positively in this second test. Compared to classic allergic reactions, our patients with local allergies experienced symptoms for shorter periods [10].

In 2014, Rondón et al. [8], however, reported on 194 patients with local allergic nasal reactions in Spain, for whom only $6.8 \%$ of the negative skin tests became positive within 5 years. This was not significantly more frequent than in nonatopic controls (4.5\%).

Considering how our results differed from those of the study by Rondón et al. [8], the question arose as to whether the higher rate of conversions to positive skin tests that we observed would be confirmed when observing a greater number of patients over a longer period of time. We were also interested in examining the specific serum-IgE levels in such patients.

\section{Patients and Methods}

In this retrospective, follow-up study, we collected the clinical records of patients who had had a positive reaction to nasal allergen provocations and a negative skin test reaction to the same allergen between 1982 and 2012 at the Malteser Lungen- und Allergiezentrum Bonn (Praxis Prof. Sennekamp, Bonn, prior to 2007). We selected 42 patients who had repeated the skin test once or several times in the years following the first test. Most of these patients had also been evaluated in a previous study [10]. Eighteen patients were $\leq 25$ years old and 24 patients were $>25$ years old. Out of the total of 42 patients, $25(60 \%)$ were female. All patients had had seasonal or perennial allergic symptoms in the upper and/or lower airways and had been treated accordingly. Skin tests were performed by the usual modified SPT or i.c. techniques [11]. Five patients had positive nasal tests for more than one allergen with negative skin reactions (tables 1,2 ).

Skin tests were conducted on all 42 patients for mixtures of grass pollen, tree pollen (birch, hazel and alder), weed pollen (mugwort (Artemisia vulgaris), plantain, orache, goosefoot and nettle), rye pollen, Alternaria, Aspergillus, Penicillium, Cladosporium, Mucor and Fusarium, the mites Dermatophygoides pteronyssinus and D. farinae, a mixture of feathers (goose and duck) and two mixtures of animal danders (dog, cat, horse, rabbit, goat and sheep). Additional skin tests (e.g. for food allergens) conducted on these patients were not considered in this study.

The panel of allergens used for nasal provocation contained grass pollen mix, tree pollen mix (birch, hazel and alder), D. ptero- 
Table 2. Skin tests and specific IgE in patients with positive nasal provocation and whose skin tests remained negative

\begin{tabular}{|c|c|c|c|c|c|}
\hline No. & Age, years ${ }^{\mathrm{a}}$ & $\begin{array}{l}\text { Elapsed time between } \\
\text { initial and last skin test }\end{array}$ & EAST class $^{\mathrm{b}}$ & Allergen & SPT/i.c. \\
\hline 1 & 3 & 1 & & mites & SPT/SPT \\
\hline 2 & 9 & 5 & & grass pollen & $\mathrm{SPT} / \mathrm{SPT}$ \\
\hline 3 & 56 & 3 & & cat & i.c./i.c. \\
\hline 4 & 13 & 1 & & grass pollen/tree pollen & i.c./i.c. \\
\hline 5 & 42 & 2 & & mites & i.c./i.c. \\
\hline 6 & 40 & 5 & & $\operatorname{dog}$ & i.c./i.c. \\
\hline 7 & 51 & 11 & & mites & i.c./i.c. \\
\hline 8 & 30 & 2 & $-/ 0$ & mites & i.c./i.c. \\
\hline 9 & 35 & 14 & $-/ 0$ & mites & i.c./i.c. \\
\hline 10 & 30 & 10 & $0 / 0$ & mites & i.c./i.c. \\
\hline 11 & 22 & 1 & & mites & i.c./i.c. \\
\hline 12 & 21 & 13 & $-/ 0$ & mites/sheep wool/cat & i.c./i.c. \\
\hline 14 & 51 & 10 & $-/ 0$ & feathers & i.c./i.c. \\
\hline 15 & 48 & 5 & & sheep wool & i.c./i.c. \\
\hline 16 & 24 & 9 & & grass pollen & SPT/i.c. \\
\hline 17 & 46 & 9 & & mites & i.c./i.c. \\
\hline 18 & 17 & 3 & & mites & i.c./i.c. \\
\hline 19 & 44 & 3 & & mites & i.c./i.c. \\
\hline 20 & 70 & 3 & $0 / 0$ & mites & i.c./i.c. \\
\hline 21 & 55 & 3 & & grass pollen & i.c./SPT \\
\hline 22 & 28 & 2 & & mould & i.c./i.c. \\
\hline 23 & 59 & 8 & & mites & i.c./i.c. \\
\hline 24 & 42 & 9 & $-/ 0$ & mites/sheep wool & i.c./i.c. \\
\hline 25 & 44 & 11 & & mites & i.c./i.c. \\
\hline
\end{tabular}

nyssinus, feather mix (goose and duck), cat, dog, sheep and a mold mixture (Alternaria, Aspergillus, Cladosporium, Penicillium, $\mathrm{Mu-}$ cor, and Fusarium).

Commercial allergens (Bencard) were used for the skin and nasal tests. Specific IgE determination via fluorescence enzyme immunoassay (FEIA), a special EAST, was performed using the Phadia (Pharmacia, Thermo-Fisher) CAP system (CAP-FEIA) according to the manufacturer's instructions.

Nasal challenges were conducted during an asymptomatic period by spraying the negative control solution into one nostril and the diluted allergen into the other nostril. When the control was tolerated without symptoms and without a change in the nasal resistance, the allergen was sprayed in diluted form. Depending on the anamnesis, the allergen was diluted at a rate of 1:1,000 (for heavy symptoms) or 1:10 (for slight symptoms). When the test was negative, the allergen dose rate was increased at most up to the undiluted allergen. Before the challenges and 2 and $10 \mathrm{~min}$ after spraying the control and allergen dilutions, symptoms (sneezing, rhinorrhea, itching, watery eyes, burning in the nose, an itchy throat and headaches) [10] were recorded, and nasal resistance was measured using rhinomanometry $[12,13]$. For this purpose, the Siemens Siregnost FD5 measuring instrument was used in combi- nation with the Hewlett-Packard $\mathrm{x} / \mathrm{y}$-reader, and different sizes of AMBU nasal masks. Provocation was deemed positive when nasal resistance rose to at least double its initial value and at least one clinical symptom appeared. When nasal resistance did not increase or rhinomanometry was impossible to perform (e.g. in young children), provocation was deemed positive when at least three symptoms appeared [10, 14-18].

Proportions were tested using the $\chi^{2}$ test. For the comparison of continuous variables, the median and range are given and the nonparametric Wilcoxon rank-sum test was used. The probability of conversion was determined by product-limit Kaplan-Meier estimates. As the skin tests were not performed regularly, in the case of converted patients, the moment of conversion was estimated by the middle of the period from the last negative to the first positive skin test observed. Censored patients were considered with the time period until the last negative skin test. The survival distribution function of conversion is given and the probability of conversion is the difference to 1.0. For the comparison of Kaplan-Meier curves, the log-rank test was chosen. Age groups were defined as: $\leq 25$ years and $\geq 26$ years. Statistical significance was defined as $p<$ 0.05 . The statistical analyses were performed using SAS 9.2 (SAS Institute, Cary, N.C., USA). 
Table 3. Characteristics of the study patients

\begin{tabular}{|c|c|c|c|c|}
\hline & \multirow[t]{2}{*}{ Total $(n=42)$} & \multicolumn{2}{|c|}{ Conversion to positive skin test } & \multirow{2}{*}{$\frac{\text { Test between group }}{\text { p value }^{1}}$} \\
\hline & & yes $(n=17)$ & no $(\mathrm{n}=25)$ & \\
\hline \multicolumn{5}{|l|}{ Length of observation } \\
\hline $1-5$ years & $47.6(20)$ & $35.3(6)$ & $56.0(14)$ & 0.381 \\
\hline $6-10$ years & $26.2(11)$ & $29.4(5)$ & $24.0(6)$ & \\
\hline$>10$ years & $26.2(11)$ & $35.3(6)$ & $20.0(5)$ & \\
\hline Age $\leq 25$ years & $42.9(18)$ & $58.8(10)$ & $32.0(8)$ & 0.085 \\
\hline Age $\geq 26$ years & $57.1(24)$ & $41.2(7)$ & $68.9(17)$ & \\
\hline \multirow[t]{2}{*}{ Local allergy to pollen } & $33.3(14)$ & $52.9(9)$ & $20.0(5)$ & 0.026 \\
\hline & Median (min.; max.) & Median (min.; max.) & Median (min.; max.) & $\mathrm{p}$ value ${ }^{2}$ \\
\hline Length of observation & $7.5(1 ; 27)$ & $8(2 ; 27)$ & $5(1 ; 13)$ & 0.169 \\
\hline Age & $31.5(3 ; 70)$ & $25(3 ; 55)$ & $40(3 ; 70)$ & 0.075 \\
\hline
\end{tabular}

\section{Results}

A total of 42 patients were studied, and the duration of follow-up varied from 1 to 27 years. Nearly half were observed for $\leq 5$ years (tables $1-3)$. Seventeen patients $(40 \%$, 8 males and 9 females) who initially had negative skin reactions converted to positive skin reactions at a later date (table 1). Once positive, reactions remained positive in further controls (not listed). In the remaining 25 patients (9 males and 16 females), all subsequent skin tests were negative (table 2). The duration of observation did not differ statistically between the conversion and nonconversion group (table 3 ).

The median of censored time to failure was 5 years and the estimated time to failure ranged from 1 to 17 years (median: 5.5 years). We observed that $25 \%$ of this population switched within 5.5 years and $50 \%$ within 10.5 years (fig. 1 ).

A trend was observed of more patients of $<26$ years old in the conversion group (table 3 ); the proportion of younger patients ( $\leq 25$ years) with results that switched was $59 \%$ in comparison to $32 \%$ of the patients with persistent negative skin tests.

The age of patients whose test results switched from negative to positive ranged from 3 to 55 years, with a median age of 25 years at the initial test. The corresponding median age of the patients whose test results remained negative was 40 years, and their age at the initial testing ranged from 3 to 70 years. The difference in median age was not significant at a level of $5 \%(p=0.075)$.

Local Allergic Nasal Reactions
In the cohort study, the proportion of 'switch' patients was $56 \%(10 / 18)$ in young patients ( $\leq 25$ years) in comparison to $29 \%(7 / 24)$ in older patients ( $\geq 26$ years). The probability of conversion, given by Kaplan-Meier curves (fig. 2) was statistically significant higher for younger $(\leq 25$ years old) than for older patients $(p=0.030)$.

Pollen was the most frequent allergen ( 9 reactions) in the first group of patients whose skin reactions switched to positive, followed by mites (7 reactions; table 1 ). Conversely, mites prevailed in patients whose test results remained negative, with 15 reactions compared to 7 for pollen (table 2). Reactions to pollen at the initial test was statistically significant higher in the conversion group (53 vs. $20 \%, \mathrm{p}=0.026$; table 3).

Eleven patients underwent additional skin tests in the period between the initial negative skin test and the positive skin test (table 1). All intermediate skin test results were negative. The time periods between the initial and intermediate skin tests are listed in table 3 . The intermediate skin tests narrow down the period during which the conversion from negative to positive occurred. The switch from negative to positive took place at some point in time between the values in the first and second column of table 1. A review of the first 4 patients shows that the switch from negative to positive skin test was, at the earliest, 7, 8 or 11 years after the initial skin test.

Moreover, we observed positive skin reactions to at least one additional allergen of the applied skin test panel in 23 out of the 42 patients (55\%). These reactions were 


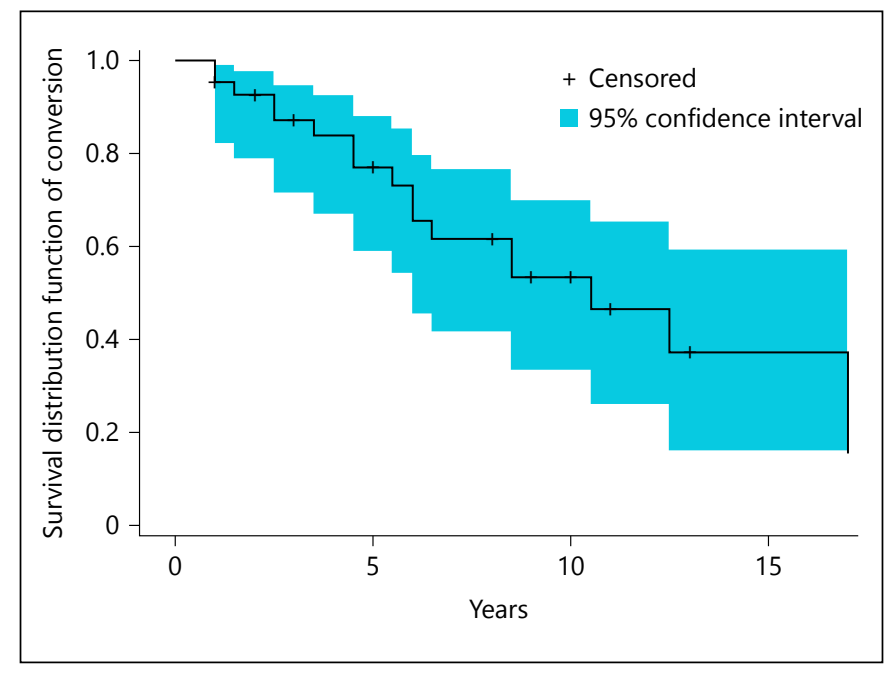

Fig. 1. Kaplan-Meier curve with $95 \%$ confidence interval. The time of conversion was estimated as the middle of the period between the last negative to the first positive skin test observed, or in censored patients as the time until the last negative skin test.

more frequent in patients with converted skin reactions $(76 \%, 13 / 17)$ than in patients with persistently negative skin tests $(40 \%, 10 / 25)$.

Specific IgE was only detectable in 2 of 17 patients (mites, grass pollen) (12\%; tables 1,2$)$. Skin tests of the two IgE-positive patients had converted from negative to positive skin reactions (table 1). No specific IgE, however, could be detected in patients whose skin tests remained negative (table 2).

\section{Discussion}

Our impression of a rather high conversion rate (6/15) [10] from negative to positive skin tests in local allergic rhinitis in our 1987 study was confirmed, with a conversion rate of $40 \%$. As mentioned above, Rondón et al. [8] followed 194 patients with local allergy of recent onset and $<2$ years of evolution showing a lower conversion rate $(6.8 \%)$ in adult patients and in 130 controls (4.5\%).

In another study published in 2009, Rondón et al. [9] observed a conversion rate from negative to positive skin tests of $21 \%$ and serum-specific IgE in nonallergic rhinitis patients between 3-7 years after the initial evaluation. However, in that particular study, the presence of local allergic rhinitis was not explored by nasal provocation [9].

Our study describes, for the first time, a conversion from local to classic systemic allergic rhinitis $>7$ years af-

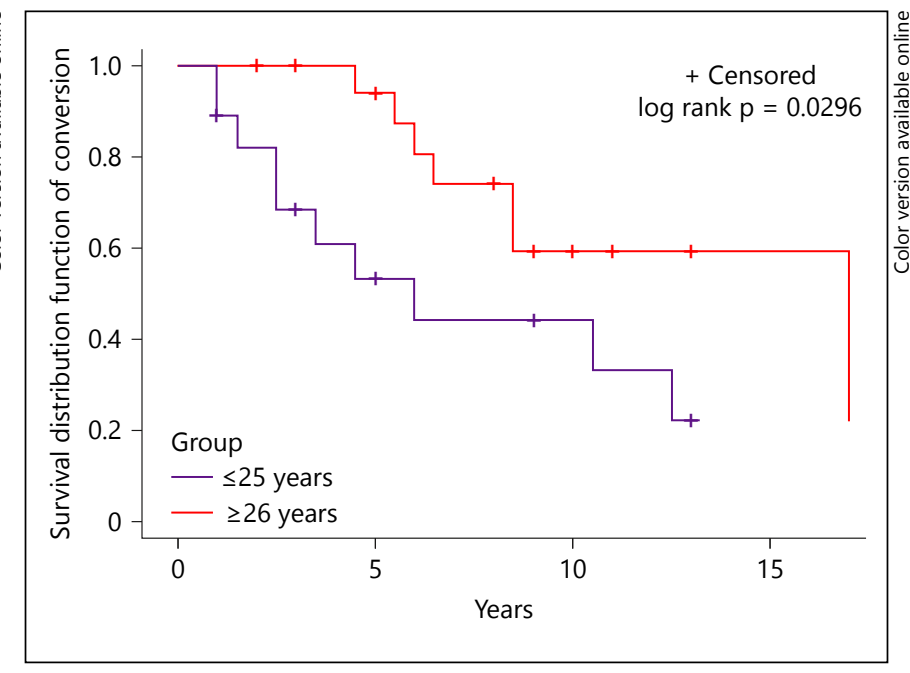

Fig. 2. Kaplan-Meier curves according to age group. The time of conversion was estimated as the middle of the period between the last negative to the first positive skin test observed, or in censored patients as the time until the last negative skin test.

ter the initial evaluation. In contrast to the studies conducted by Rondón et al. $[8,9]$, this retrospective study did not involve a control group. The absence of a control group does not diminish the results of this study, because a conversion rate of $40 \%$ is an evident increase in comparison to the conversion rate in healthy subjects, i.e. only $17 \%$ of the population in the region where the study was conducted had positive skin tests on the aeroallergens tested here [19].

Based on the fact that 17 of the 42 patients followed in our study converted from negative to positive skin tests in an estimated time period of 1-17 years, it may be assumed that $50 \%$ will switch from negative to positive skin reactions within 10 years (fig. 1).

We frequently used i.c. tests, while Rondón et al. [8] invariably applied the SPT technique, which could influence negative skin test rates and rates of conversion. The more sensitive i.c. test may generate negative skin tests less frequently [20]. With regard to the specific IgE, the conversion rate of $12 \%$ observed in our study was higher than in their study (1.1\%) [8], they did, however, test patients who were completely negative for all allergens. The explanatory power of our results may have been limited by the small number of patients.

Interestingly, pollen was the most common allergen in the group of patients whose skin tests converted from negative to positive, while there was a predominance of mites in patients whose skin tests remained negative (ta- 
bles 1,2). All in all, and congruent with the study by Rondón et al. [7, 8], house dust mites were the most frequent allergens, as evaluated in our previous study [10]. The predominance of the female gender in local allergic reactions was less pronounced in our study $(60 \%)$ than in the study by Rondón et al. [8] (69\%).

Those of our patients that had repeated skin tests remained symptomatic the whole time and were therefore in our long-time care. We cannot judge to what extent the patients who left our care became asymptomatic. In our 1987 study, local allergy patients had suffered from symptoms for an average of 2.5 years while those with classic systemic allergies had suffered for 4.5 years [10]. At that time, we had suggested that these local allergic reactions may be an early stage of classic allergic reactions. Our study demonstrates that younger patients $(\leq 25$ years old) with local allergies have a greater predisposition to acquire a systemic allergy than older patients (fig. 2).

Most of our patients with local allergies not only had local allergic reactions to $\geq 1$ allergens but, in $55 \%$ of cases, also showed positive skin reactions to other allergens in the skin test panel. The Spanish patients in the study by Rondón et al. [8] were negative in the skin test for all applied allergens, so our patients differed in this respect, an important fact to take into account when considering the results of these studies.

Moreover, Simola et al. [21] observed that skin reactions in classic allergic rhinitis decline over time. This contrasts with our observation of increasing skin tests in local allergy.
Using allergen provocations with multiple aeroallergens, local allergic rhinitis, at $26 \%$, is more common than nonallergic rhinitis $(11 \%)[7,22]$. Rondón found classic allergic rhinitis to be the most widespread form of rhinitis at $63 \%$ [7]. The clinical symptoms of local allergic and classic allergic reactions do not differ significantly, except that the former have an earlier onset [7]. In nonallergic rhinitis, rhinorrhea and obstruction of the nose are more frequent, older patients predominate and there is no eosinophilia and no response to antihistamines [23].

Preliminary studies of immunotherapy suggest that patients with local allergic reactions benefit from this treatment [24-26].

Our above observations reinforce the role of nasal allergen provocation and the nasal detection of specific $\operatorname{IgE}$ antibodies in the diagnostics of local allergic reactions. Overall, if nasal provocation is more frequently applied as a result of our investigation, patients will have benefited from our insights, and this is particularly true when skin tests and specific IgE are negative.

\section{Acknowledgement}

We thank Phillip Elliot and Andreas Sennekamp for help with the final English language version of the manuscript.

\section{Disclosure Statement}

The authors declare no conflicts of interest.

\section{References}

1 Rondón C, Romero JJ, Lopez S, et al: Local IgE production and positive nasal provocation test in patients with persistent nonallergic rhinitis. J Allergy Clin Immunol 2007;119:899905.

$\checkmark 2$ Lopez S, Rondón C, Torres MJ: Immediate and dual response to nasal challenge with $D$. pteronyssinus in local allergic rhinitis. Clin Exp Allergy 2009;40:1007-1014.

3 Rondón C, Canto G, Blanca M: Local allergic rhinitis: a new entity, characterization and further studies. Curr Opin Allergy Clin Immunol 2010;10:1-7.

4 Powe DG, Bonnin AJ, Jones NS: 'Entopy': local allergy paradigm. Clin Exp Allergy 2010;4: 987-997.

5 Khan DA: Allergic rhinitis with negative skin test: does it exist? Allergy Asthma Proc 2009; 30:465-469.
6 Kim YH, Park CS, Jang TY: Immunologic properties and clinical features of local allergic rhinitis. J Otolaryngol Head Neck Surg 2012;41:51-57.

7 Rondón C, Campo P, Galindo L, et al: Prevalence and clinical relevance of local allergic rhinitis. Allergy 2012;67:1282-1288.

-8 Rondón C, Campo P, Zambonino MA, Blanca-Lopez N, Torres MJ, Melendez L, Herrera R, Gueant-Rodriguez RS, Gueant JL, Canto G, Blanca M: Follow-up study in local allergic rhinitis shows a consistent entity not evolving to systemic allergic rhinitis. J Allergy Clin Immunol 2014;133:1026-1031.

9 Rondón C, Doña I, Torres MJ, Campo P, Blanca M: Evolution of patients with nonallergic rhinitis supports conversion to allergic rhinitis. J Allergy Clin Immunol 2009;123: 1098-1102.
10 Sennekamp J, Nöldeke H, Berdel D: Positiver nasaler Provokationstest bei negativem Hauttest. Allergologie 1987;10:167-172.

11 Dreborg S, Frew A: EAACI subcommittee on skin tests. Position paper: allergen standardization and skin tests. Allergy 1993;48(sup$\mathrm{pl}): 48-82$.

12 Schlenter WW: Methoden zum Nachweis einer allergischen Sofortreaktion der Nasenschleimhaut. Allergologie 1983;6:16-21.

13 Berdel D, Gast R: Registrierung der Nasenwiderstandsänderung mit dem Oszillationsverfahren während der nasalen Provokation mit Allergenen. Allergologie 1979;2:252254.

14 Berdel D, Koch U: Die Bedeutung der 'nasalen Provokation' in der Allergiediagnostik und ihre Objektivierung mit der Rhinomanometrie. Laryng Rhinol 1981;60:491-495. 
15 Clement PA: Committee report on standardization of rhinomanometry. Rhinology 1984; 22:151-155

16 Malm L, van Wijk GR, Bachert C: Guideline for nasal provocation with aspects on nasal patency, airflow, and airflow resistance. International Committee on Objective Assessment of the Nasal Airways, International Rhinologic Society. Rhinology 2000;38:1-6.

17 Andersson M, Greiff L, Svensson C, Persson $\mathrm{C}$ : Various methods for testing nasal responses in vivo: a critical review. Acta Otolaryngol Stockh 1995;115:705-713.

18 Niggemann B, Berdel D, Urbanek R: Nasaler provokationstest; in Wahn U, Seger R, Wahn V, Holländer GA: Pädiatrische Allergologie und Immunologie. Munich, Urban and Fischer, 2005, pp 291-294.
19 Nicolai T, Bellach B, Mutius EV, Thefeld W, Hoffmeister H: Increased prevalence of sensitization against aeroallergens in adults in West compared with East Germany. Clin Exp Allergy 1997;27:886-892.

20 Di Berardino F: Allergic or nonallergic rhinitis? Letter to the editor. J Allergy Clin Immunol 2009; 124:620.

21 Simola M, Holopainen E, Malmberg $\mathrm{H}$ : Changes in skin and nasal sensitivity to allergens and the course of rhinitis; a long-term follow-up study. Ann Allergy Asthma Immunol 1999;82:152-156.

22 Rondón C, Campo P, Herrera R, et al: Nasal allergen provocation test with multiple aeroallergens detects polysensitization in local allergic rhinitis. J Allergy Clin Immunol 2011; 128:1192-1197.
23 Di Lorenzo G, Pacor ML, Amodio E, et al: Differences and similarities between allergic and nonallergic rhinitis in a large sample of adult patients with rhinitis symptoms. Int Arch Allergy Immunol 2011;155:263270 .

24 Kahlert S, Buschfort R, Sennekamp J: Hyposensibilisierung Hauttest negativer Inhalationsallergien. Allergologie 1990;13:76.

25 Rondón C, Lopez S, Lisbona J, et al: Immunotherapy with grass pollen in patients with 'local allergic rhinitis'. J Allergy Clin Immunol 2009;125(suppl 1):AB37.

26 Rondón C, Blanca-Lopez N, Aranda A, et al: Local allergic rhinitis: allergen tolerance and immunologic changes after preseasonal immunotherapy with grass pollen. J Allergy Clin Immunol 2011;127:1069-1071. 